\title{
Translational Andrology and Urology is indexed in SCIE: a milestone for the development of TAU
}

\author{
Editorial Office \\ Editorial Office, AME Publishing Company \\ Correspondence to: Editorial Office. AME Publishing Company. Email: tau@amepc.org.
}

Submitted Dec 13, 2018. Accepted for publication Dec 13, 2018.

doi: $10.21037 /$ tau.2018.12.03

View this article at: http://dx.doi.org/10.21037/tau.2018.12.03

On December 12, 2018, we received the good news from Clarivate Analytics (former Thomson Reuters Intellectual Property and Science Business) that Translational Andrology and Urology (TAU) has been indexed in Science Citation Index Expanded (SCIE) and articles published since 2016 will all be included.

TAU is the 8th journal of AME Publishing Company included by SCIE, following the other seven sister journals:

* Fournal of Thoracic Disease (http://jtd.amegroups.com)

* Translational Cancer Research (http://tcr.amegroups. com)

* Annals of Translational Medicine (http://atm.amegroups. com)

* Hepatobiliary Surgery and Nutrition (http://hbsn. amegroups.com)

- Quantitative Imaging in Medicine and Surgery (http:// qims.amegroups.com)

- Annals of Cardiothoracic Surgery (http://www.annalscts. $\mathrm{com} /$ )

* Translational Lung Cancer Research (http://tlcr. amegroups.com)

Led by Prof. Ying-Lu Guo and Prof. Tom F. Lue as the Editors-in-Chief, TAU is further supported by a strong lineup of over 70 experts worldwide in the field of andrology and urology as the Editorial Board members
(Figure 1). TAU upholds AME's philosophy and standards in running journals. It values the international diversity of Editorial Board members and authors (Figures 2,3) to ensure the quality of published articles. By publishing high-quality articles, TAU made lots of progress in the past six years, such as the article numbers (Figure 4), the growing citation and readers (Figures 5,6).

Speaking of high-quality articles, we also would like to take this chance to extend our heartfelt gratitude to another group of experts-our Guest Editors, who have been actively involved in the forefront of scientific research and clinical practice and devoted their precious time and effort to organize the excellent focused issues (Tables 1,2) to demonstrate the cutting-edge knowledge, techniques, and discussions in their professional fields to our readers.

Moreover, there are still our Section Editors, Reviewers and Readers worldwide that we could not express our appreciation one by one.

Currently, TAU is indexed in PubMed/PubMed Central, Scopus and SCIE. We can't achieve this without the continuous support and contributions of TAU's editorial board members, guest editors, authors, reviewers and readers. We here would like to extend our sincere gratitude to all the contributors. We will keep striving to publish high-quality articles and make $T A U$ to the forefront in the field of andrology and urology. 

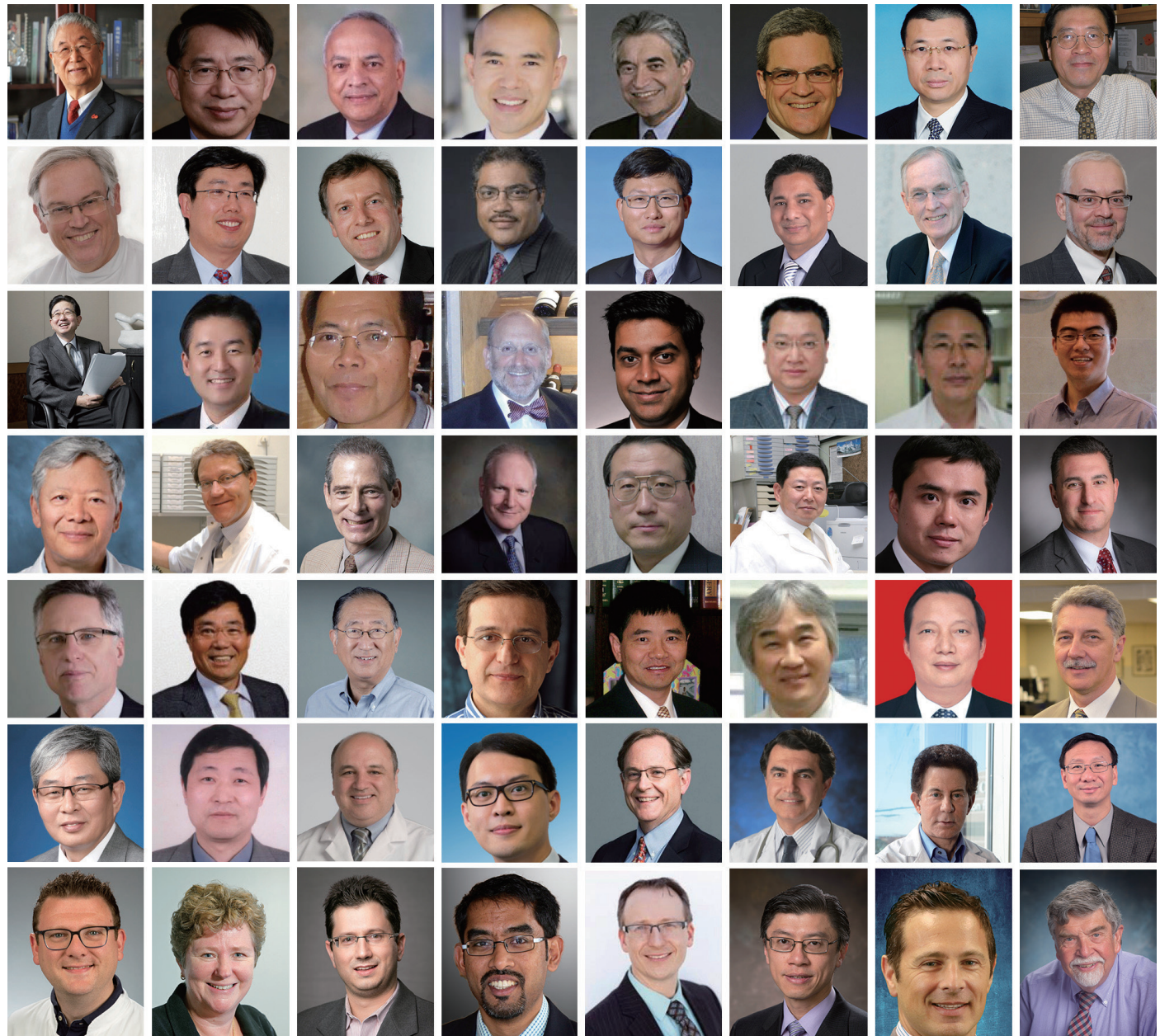

Figure 1 A collage featuring the Editors-in-Chief and Editorial Board members of TAU.

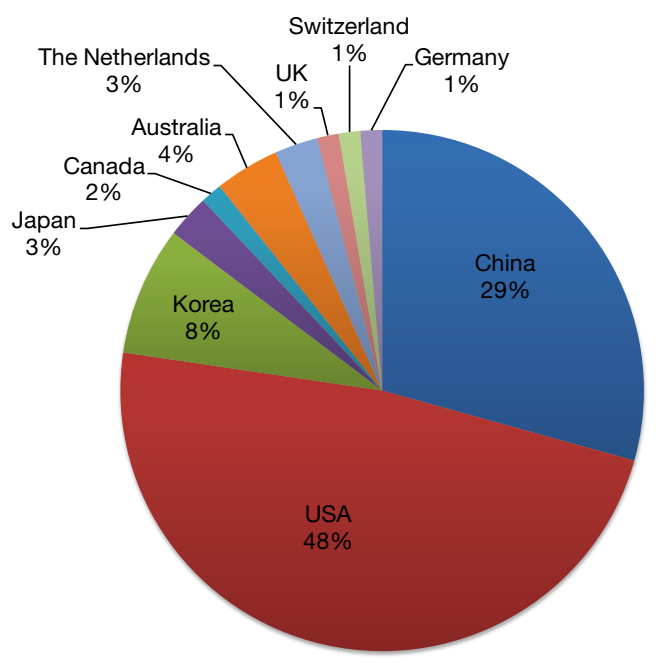

Figure 2 Geographical distribution of TAU's Editorial Board members (updated on Dec. 12, 2018).

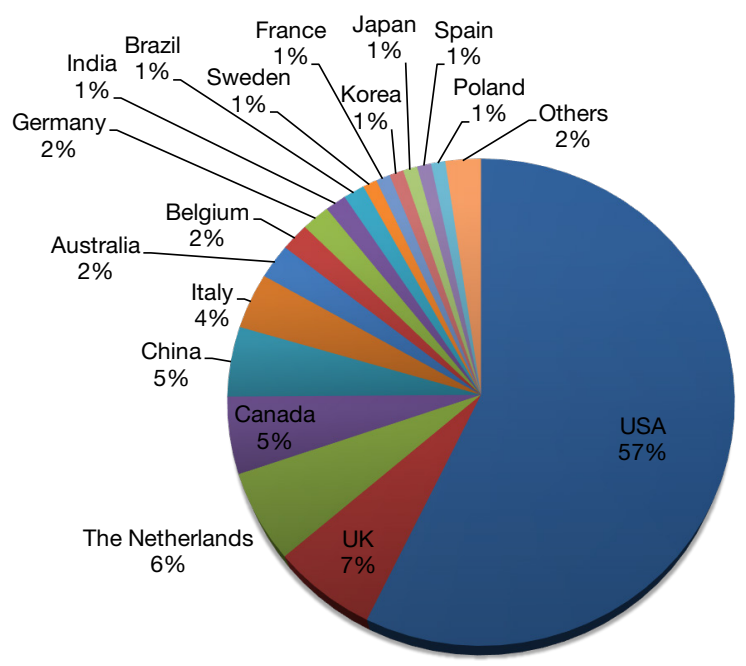

Figure 3 Geographical distribution of TAU's Corresponding Authors in 2018 (updated on Dec. 12, 2018). 


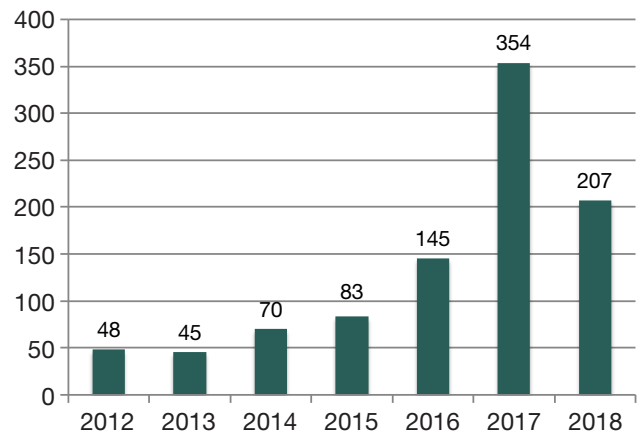

Figure 4 Number of published articles (updated on Dec. 12, 2018).

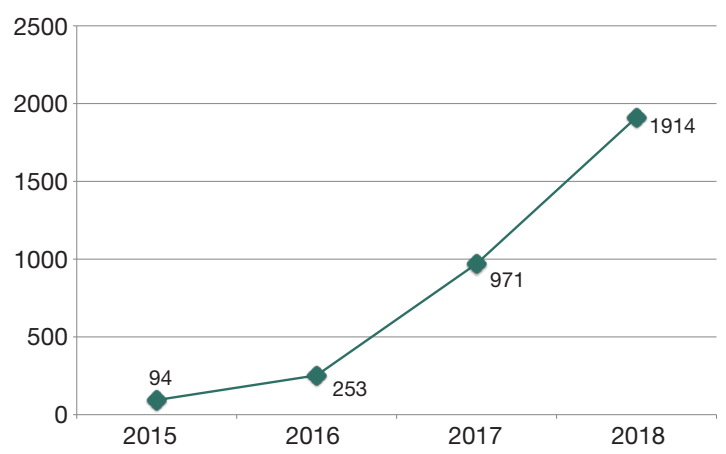

Figure 5 Citation of TAU articles by articles indexed in Web of Science Core Collection (data were collected from Web of Science Core Collection on Dec. 13, 2018).

Retrieval: Total

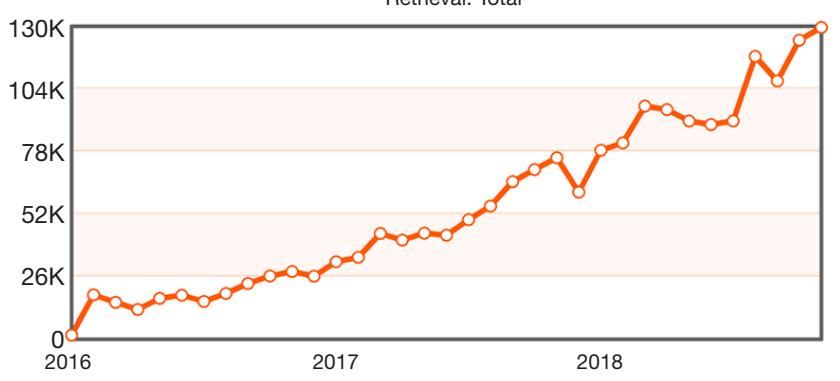

Figure 6 Retrieval of TAU in PubMed is increasing and it also presents the growing readers of TAU (data were collected from PMC Publisher Services on Nov. 30, 2018).

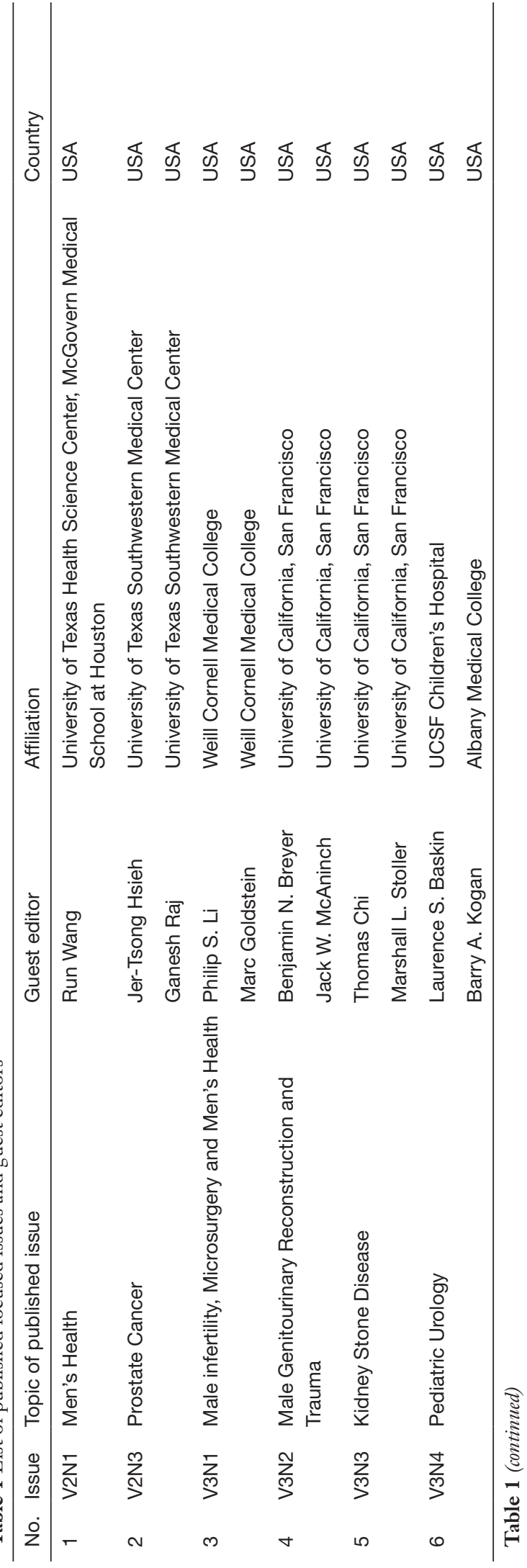

(c) Translational Andrology and Urology. All rights reserved. 

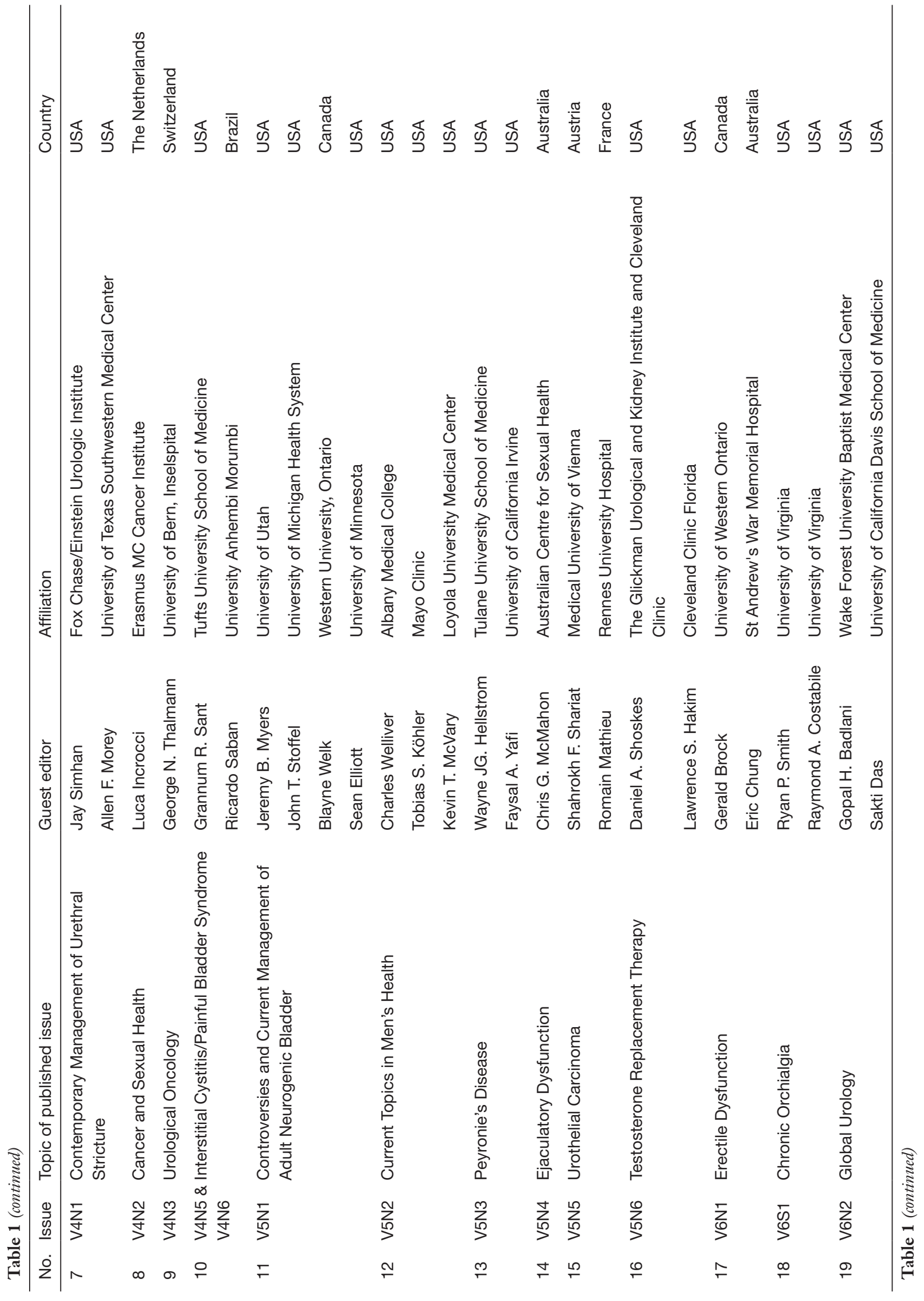


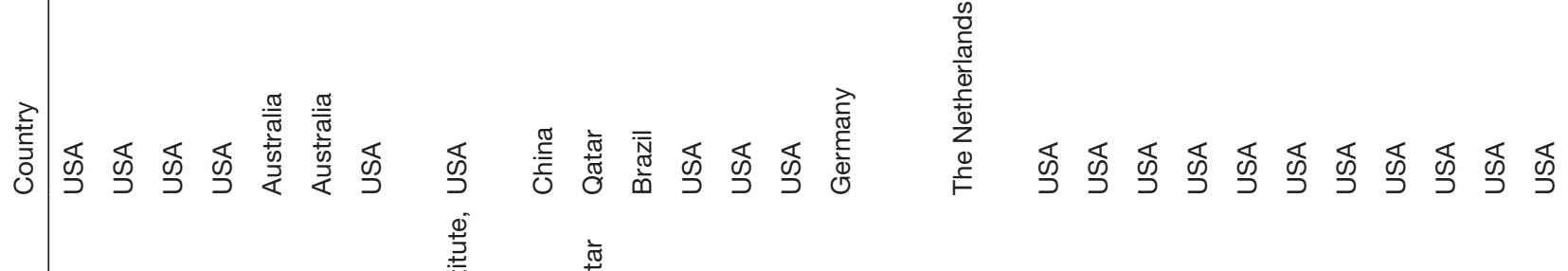
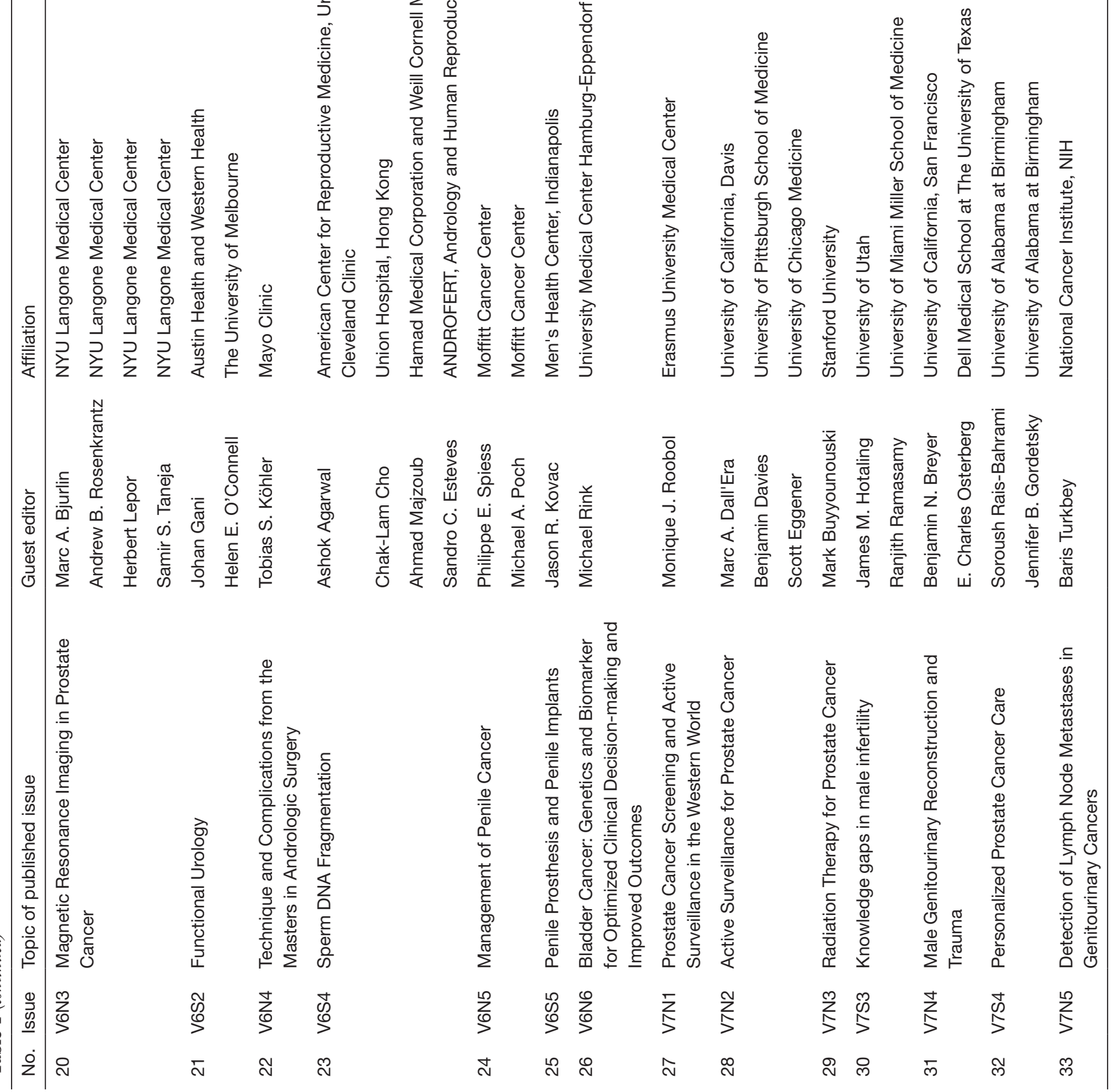
Table 2 List of upcoming focused issues and guest editors

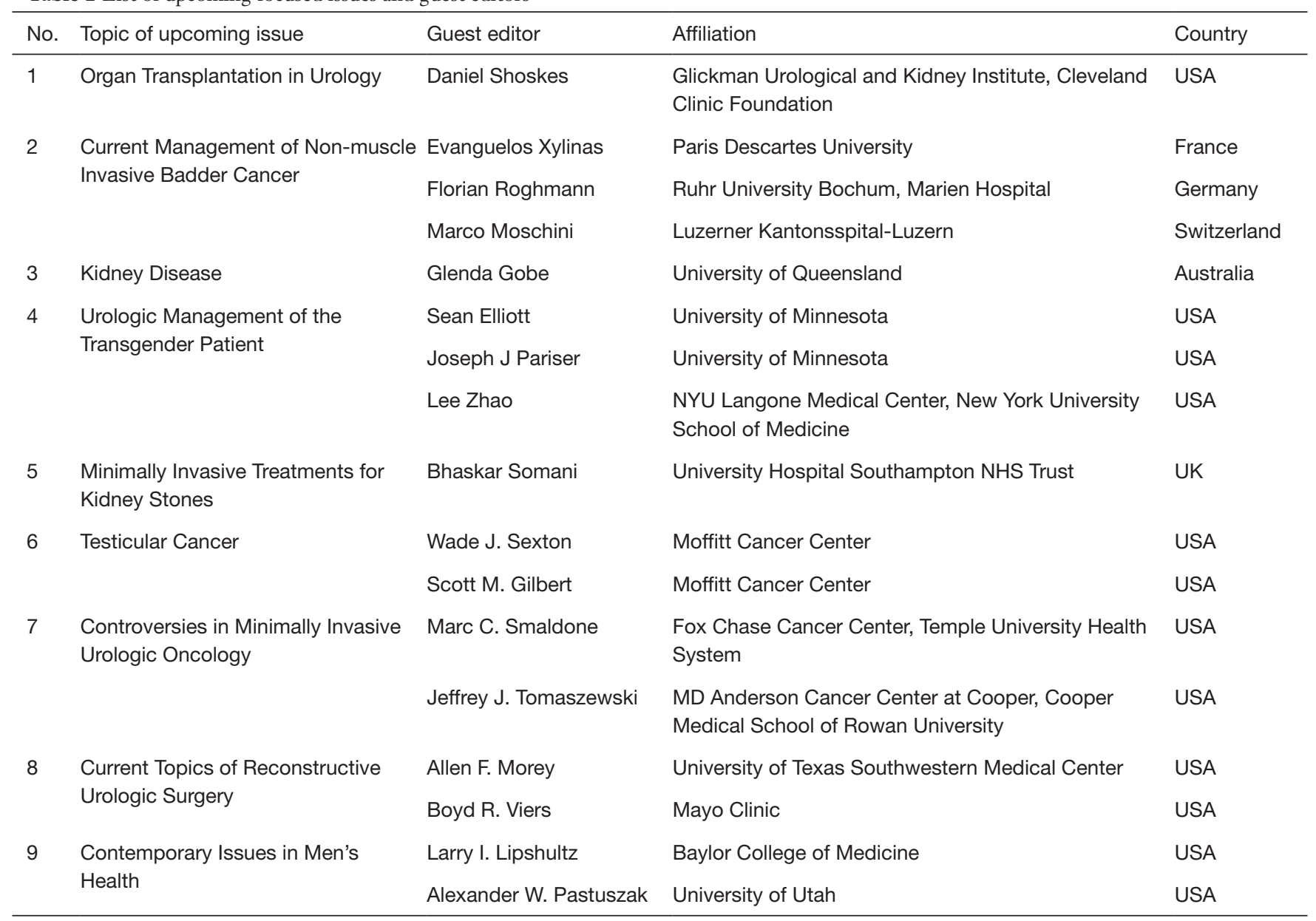

\section{Acknowledgements}

None.

Cite this article as: Editorial Office. Translational Andrology and Urology is indexed in SCIE: a milestone for the development of TAU. Transl Androl Urol 2018;7(Suppl 6):S770-S775. doi: 10.21037/tau.2018.12.03

\section{Footnote}

Conflicts of Interest: The authors have no conflicts of interest to declare. 